\title{
Influences of Exit Advance Guide Signs on the Trajectory and Speed of Passenger Cars in Highway Tunnels
}

\author{
Ting Shang, ${ }^{1}$ Peng Wu, ${ }^{1}$ Guan Lian $\mathbb{D}^{2},{ }^{2}$ and Qijin Sheng ${ }^{3}$ \\ ${ }^{1}$ School of Traffic \& Transportation, Chongqing Jiaotong University, Chongqing 400074, China \\ ${ }^{2}$ School of Civil Engineering, Chongqing Jiaotong University, Chongqing 400074, China \\ ${ }^{3}$ China Railway Major Bridge Reconnaissance and Design Institute Co., Ltd., Wuhan, Hubei 430056, China
}

Correspondence should be addressed to Guan Lian; lianguan370@163.com

Received 26 June 2021; Revised 19 October 2021; Accepted 26 October 2021; Published 16 November 2021

Academic Editor: Yajie Zou

Copyright ( $\odot 2021$ Ting Shang et al. This is an open access article distributed under the Creative Commons Attribution License, which permits unrestricted use, distribution, and reproduction in any medium, provided the original work is properly cited.

The driving behavior in highway tunnels is more complicated than that in regular roadbed sections because the former is usually affected by black and white hole effects, tunnel clearance, and bad illumination. Unfortunately, the current Chinese criteria and the Uniform Traffic Control Equipment Manual (MUTCD) 2009 guidelines provide no clear method for setting exit advance guide signs in highway tunnels. Hence, a driving simulator-based experiment was conducted in the current study to analyze the effects of exit advance guide signs on the trajectory, speed, and acceleration of passenger cars in a highway tunnel under three different service levels. It was found that when the service level is first service level, second service level, and third service level, the setting of the exit advance guide signs made the initial transverse location of the vehicle from the tunnel exit advance by $13.39 \%, 21.20 \%$, and $5.73 \%$, the lane change distance is shortened by $6.34 \%, 20.18 \%$, and $15.34 \%$, the average speed is decreased by $1.44 \%, 2.40 \%$, and $0.08 \%$, and the acceleration is decreased to $-0.10 \mathrm{~m} \cdot \mathrm{s}^{-2},-0.11 \mathrm{~m} \cdot \mathrm{s}^{-2}$, and $-0.06 \mathrm{~m} \cdot \mathrm{s}^{-2}$. Thus, the exit guide signs in the tunnel played a certain optimization role in improving the traffic flow state of the section and reducing the traffic accident rate.

\section{Introduction}

In the past ten years, many mountain highways have been built in China. Limited by terrain conditions, the number of tunnels is increasing. It is reported that the accident rate in tunnels is lower than that on highways; however, the accident fatality rate is higher $[1,2]$. When vehicles come out of a tunnel, white hole effects, frequent lane changes, and traffic flow interweaving can easily cause accidents. However, due to tunnel space limitations, the setting of these signs in tunnels quite differs from that in regular roadbed sections. The influence of exit advance guide signs in highway tunnels is closely related to traffic safety. Exit advance guide signs are a crucial aspect of highway design because they are essential information sources for highway users to calibrate their driving behavior and evaluate route possibilities [3]. However, the current criteria provide no clear method for setting exit advance guide signs in highway tunnels.
Highway tunnels are very common in mountainous areas. Tunnels can constitute about $90 \%$ of a highway, with only $10 \%$ of original roadbed sections. For example, the Chengkai highway in Chongqing bridges and tunnels account for $80 \%$, and original roadbed sections only account for $20 \%$ [4], because the driver in the tunnel-interchange closely spacing section needs to not only experience the "light adaptation" stage but also to confirm the traffic signs along the line. When the driving environment is complicated, the driver needs to increase the additional driving load to deal with this information [5-8]. Therefore, the driving behavior in highway tunnels is more complicated than that in original roadbed sections, leading to different traffic flow characteristics and accident risk levels. Unfortunately, the current Chinese criteria [9-12] and the Uniform Traffic Control Equipment Manual (MUTCD) 2009 guidelines provide no clear method for setting exit advance guide signs in tunnels. Driving behavior is one of the important 
indicators to test whether the setting of road signs is reasonable, and driving speed is the direct embodiment of driving behavior and the basis of traffic sign design in tunnels [13]. However, only driving speed cannot reasonably explain the relationship among wrong driving behavior, road characteristics, and traffic accidents; hence, vehicle trajectories also should be detected to evaluate the traffic system effect on the vehicle driving state [14]. The proper understanding of the trajectory and speed of passenger cars inside and outside of highway tunnels can help engineers to propose an effective design method of exit advance guide signs.

Exit advance guide signs in tunnels can significantly improve the safety in highway tunnel-interchange sections [15]. There are many researches on tunnel exit advance guide signs. However, very few studies have discussed the setting methods of separated exit guide signs on the trajectory and speed of cars in highway tunnel-interchange sections. The study proposed a separate exit guide sign, which included location and distance signs. Location signs of Chinese characters with a height of $40 \mathrm{~cm}$ and a width of $20 \mathrm{~cm}$ were set on the top of the tunnel, and distance signs with a character height and width of $1.5 \mathrm{~m}$ and a total sign length of $22.5 \mathrm{~m}$ were set $62.6 \mathrm{~m}$ away from location signs. Forty-two participants took part in this experiment. Vehicle trajectories out of the tunnel, vehicle speed and acceleration at $200 \mathrm{~m}$ before and after the lane line crossing position, and vehicle speed and acceleration at $200 \mathrm{~m}$ after the tunnel exit were analyzed under three different service levels to explore the influences of setting exit advance guide signs on driving behavior. This study can provide a theoretical basis for engineering applications and support the optimization of exit advance guide signs design in the tunnel.

This paper is organized as follows: Section 2 provides a literature review, Section 3 describes the method of our experiment, Section 4 shows the experimental results and discussions, and Section 5 presents our conclusions.

\section{Literature Review}

2.1. Setting Methods of Exit Advance Guide Signs in Tunnels. Due to the limitation of tunnel space, the setting of exit advance guide signs in highway tunnels is different from that in ordinary roadbed sections. Unfortunately, the current Chinese criteria [9-12] and the MUTCD 2009 guidelines provide no clear setting method for exit advance guide signs. Huang et al. [16] conducted a driving simulation experiment consisting of five design alternatives of advance guide signs and two exit ramp spacing variations. The results showed a better design of advance guide signs, enabling drivers to more easily locate destination exits and change lanes fewer times, reducing drivers' need to decelerate, and improving traffic flow. Yao et al. [17] evaluated the effectiveness of traffic guide signs at intersections and found that scheme 2 had a better impact on drivers' behavioral data. Wang and Liu [18] extracted and selected highway tunnel traffic signs based on environmental factors and reported that the proposed algorithm had good recognition results. Upchurch et al. [19] analyzed the effects of different sign setting schemes based on the geometry of a simulated tunnel and sign positions. $\mathrm{Lu}$ et al. [20] proposed the separate guide signs in tunnel exits that are placed using an eye tracker and simulation test platform. By changing the placement positions of signs, they analyzed the influence of exit advance guide signs on the driver's eye movement in the mountainous highway tunnel. Based on the ergonomics and traffic theory using the rate of change of the pupil area, Yan et al. [21] proposed a model for setting traffic signs in adjacent tunnel groups' safety. Zwahlen et al. [22] investigated the effectiveness of setting ground-mounted diagrammatic advance guide signs in urban multilanes leading to freeways. However, there has been little research on the setting methods of advance guide signs at highway tunnel exits. As bottleneck sections of road networks, frequent traffic accidents occur in tunnels $[23,24]$. Under the conditions of complex geometry and restricted warning time, alternative freeway guide signs can improve driver safety. This finding verifies Arup's conclusion that alternative road signs can induce drivers to enter the exit lane earlier, thereby reducing the probability of changing lanes and missing the exit [25].

However, highway tunnels, urban tunnels, and tunnel groups are quite different in terms of their highway service level, traffic volume, the length of the tunnel-interchange spacing section, operation speed, and tunnel illumination. In particular, tunnel groups on mountainous highways are more affected by black and white hole effects and have a greater impact on the vision and driving characteristics of drivers.

\subsection{Effects of Traffic Signs on Passenger Car Speed.} Driving behavior is one of the important indicators to test whether the setting of road signs is reasonable, and driving speed is the direct embodiment of driving behavior and the basis of road alignment design. Speed is closely related to traffic safety. When the average speed increases by $5 \%$, the injured impact increases by $10 \%$, and the fatal impact increases by $20 \%$. Studies have shown that speed has a quadratic relationship with the risk of impact, a quadratic relationship with the risk of injury, a cubic relationship with the risk of serious injury, and a quartic relationship with the risk of death. [26, 27] Therefore, driving speed can to some extent reflect the rationality of the setting of exit advance guide signs in a highway tunnel. Kazemi et al. [28] conducted 527 questionnaires that were filled up randomly in 45 days and found that driving speed, accidents in the last five years, occupation, driving time, and the number of accidents per day are the most important ones for the drivers. Malin and Luoma [29] evaluated the short- and long-term effects of speed display signs on driving speed at pedestrian crossings in a low-speed $(40 \mathrm{~km} / \mathrm{h})$ urban environment. It was found that the installation of speed displays at pedestrian crossings reduced the driving speed and contributed to the safety of pedestrians. Akbari and Haghighi [30] evaluated the effects of four different low-cost traffic-reducing measurements on driving speed and lateral distance. Van Houten and Van Huten [31] explored the effectiveness of traffic signs with the phrase "Begin Slowing Down Here" written on them in a 
transitional zone with a speed limit and observed that the number of motorists who exceeded the displayed speed was reduced. Shinar and Vogelzang [32] evaluated symbolic and text displays in highway signs in terms of their comprehension speed and accuracy. A total of 30 signs with various displays and levels of familiarity were presented, and it was noticed that the addition of texts to symbols improved the comprehension speed. Song et al. [33] collected speed data by traffic survey equipment to evaluate the present position of interchange advance guide signs. In order to overcome the empirical pitfalls of current Chinese specifications and MUTCD 2009 guidelines for determining the placement distance of freeway exit advance guide signs, Guo et al. [34] analyzed the driving maneuver of exiting traffic based on different variables, such as the number of lanes and operating speed. It was reported that the proposed distance reduced the number of lane changes in the area from the ramp nose to $500 \mathrm{~m}$ upstream by $58.93 \%$ as compared to current Chinese specifications and by $27.35 \%$ as compared to MUTCD 2009 guidelines.

However, the existing literature mainly focuses on the research between traffic signs and vehicle speed. The tunnel environment is quite different from the ordinary road section. Affected by the linear, lighting, and closed environment, the vision and sight distance in the tunnel are lower than those in the ordinary road section, and the driver's judgment on the speed is more inaccurate. Therefore, it is important to study the influence of traffic signs in tunnels on vehicle speed.

\subsection{Effects of Traffic Signs on Passenger Car Trajectory. In} practice, two types of driving behaviors are noticed-unconscious wrong driving behavior and conscious wrong driving behavior. Among them, unconscious wrong driving behavior may have a direct or indirect relationship with traffic facilities and surrounding environments. Due to driving factors, vehicle factors, and traffic environments, the real trajectory of a vehicle is different from the expected vehicle trajectory in road design. In the design of highway routes, it is assumed that vehicle trajectories are consistent with the plane alignment. However, in actual driving processes, only when a driving channel is very narrow, vehicle trajectories will be close to the middle line of the lane. When the road surface is wide, drivers have ample opportunity to choose different driving paths within the channel range [35].

The effects of traffic signs on driving behavior are not completely understood. It is known that humans react to traffic signs instinctively. Vilchez [36-38] identified which traffic signs were more ergonomic for participants based on the trajectories of participants in a tracking task. It was pointed out that the signs least representative of their meanings produced a quantitative and qualitative deviation from the center of the road than the most representative ones. Hang et al. [39] conducted a driving simulator-based experiment to understand the effects of lane-end sign distance and traffic volume on driving behavior. A conceptual model was also proposed to divide the whole lane-changing process into three stages. It was found that the last guide sign being positioned further upstream of lane dropping areas could help lower the speed variance and most drivers merged after seeing the guide sign. The number of tunnels on highways is increasing nowadays, especially in China. However, the current criteria and guidelines provide no clear setting method for exit advance guide signs. Effective advance guide signs would contribute to the improved service level, road capacity, and operation of highways. Some scholars have studied advanced guide signs of closely spaced exit ramps on urban highways and evaluated the effectiveness of traffic guide signs at intersections. The trajectory, speed, and acceleration of the vehicle can reflect the influences of setting signs to a certain extent. Unfortunately, no research has been carried out on evaluating the exit advance guide signs in tunnels according to the trajectory and speed of passenger cars. The driving behavior in tunnels is more complicated than in roadbed sections because the former requires the cognitive processes of drivers [40, 41]. If exit advance guide signs are set on the top of a tunnel, the font size should be reduced due to the limitation of tunnel clearance. If a traffic sign is installed at the emergency parking strip end wall, heavy motor vehicles would obstruct it from being viewed by light motor vehicles. Therefore, it is necessary to study the effects of setting exit advance guide signs in a highway tunnel on the trajectory and speed of passenger cars. In this study, exit advance guide signs consisting of location and distance signs were used to analyze their influences on passenger cars.

\section{Methods}

Driving behaviors under six different working conditions were investigated by a driving simulator. A driving simulator can create nearly any driving scenario and collect vehicle speed and position data at any resolution. The speed and trajectory data of cars were collected by the driving simulator to conduct an in-depth analysis of driving behavior.

3.1. Participants. According to the method of mathematical statistics $[42,43]$, the sample size of the driver required for this simulation test is determined. This simulation experiment selected 42 participants. The sex and age of the participants were controlled by the sex and age ratio of Chinese motor vehicle drivers, 22 males and 20 females. The average age was 33 years (range 23-58). All participants obtained Chinese driving licenses, with a driving age of 1-15 years, and 18 participants' driving age of more than three years (rich driving experience), visual acuity or corrected visual acuity above 5.0, none color blindness, weak color, and good mental state. During the experiment, the participants were required to drive in a tunnel below a speed of $80 \mathrm{~km} / \mathrm{h}$ and leave the highway after seeing the exit sign for the target destination "Xue bao shan," with Chinese characters “雪宝 山.”

3.2. Test Apparatus and Driving Scenario. A driving simulator and an eye tracker were used as experimental tools. The driving simulator included the UC-win/Road simulation 
software (FORUM 8) and a driving operating system (PXNV3 Pro; Shenzhen PXN Electronics Technology Co., Ltd.). The driving operating system included a steering wheel, pedals, gears, and a handbrake controller (Figure 1). Considering the difference between the real world and driving simulator $[44,45]$, the driving simulator is used to restore the real driving environment to the greatest extent, and the test data of vehicle trajectory, speed, and acceleration are collected to evaluate the traffic sign setting method proposed in this paper.

\subsection{Test Design. In this paper, the tunnel-interchange closely} spacing section of Yuxiang highway in western mountainous areas of China is taken as the prototype. Combined with the traffic collocation and traffic volume of the real vehicle test, the UC-win/Road software is used to build the simulation test section. The simulation test section is a one-way twolane mountain highway tunnel with a design speed of $80 \mathrm{~km} / \mathrm{h}$ and a tunnel length is $1000 \mathrm{~m}$. The driving simulator is used to simulate and test the tunnel under different traffic volumes and different spacing. According to the difference in traffic collocation and traffic volume, three levels of service level are set. The traffic collocation is determined by the real vehicle experiment of Yuxiang highway. According to aerial photography records and statistical analysis, small vehicles accounted for $68.29 \%$, medium vehicles accounted for $13.93 \%$, and heavy vehicles accounted for $17.78 \%$. In order to explore the effect of the exit advance guide sign setting method proposed in this paper, considering the most unfavorable principle of driving environment, the traffic volume is set according to the maximum traffic volume under different road service levels. The maximum traffic volume corresponding to different road service levels is shown in Table 1.

At present, the traditional exit sign in the tunnel is generally set on the top of the tunnel. According to the different spacing of tunnel-interchange sections, each service level sets six working conditions. Working conditions 2, 4, and 6 are the test group, and 1,3, and 5 are the comparison group. The sign setting mode of the test group is "location sign + distance sign." The comparison group only set the "location sign," where the "location sign" is set on the top of the tunnel and the information is the location name. The "distance sign" is set on the sidewall of the tunnel, and the information is the distance of the front exit. The distance from the tunnel exit to the starting point of the ramp entry deceleration lane of working conditions 1 and 2 is $300 \mathrm{~m}$. The distance from the tunnel exit to the starting point of the ramp entry deceleration lane of working conditions 3 and 4 is $350 \mathrm{~m}$. The distance from the tunnel exit to the starting point of the ramp entry deceleration lane of working conditions 5 and 6 is $400 \mathrm{~m}$. The ramp exit deceleration lane length for each condition is set to $150 \mathrm{~m}$ with reference to "Guidelines for design of highway grade-separated intersections" (JTG/T D21-2014) [12]. The specific test scheme is shown in Table 2. The driving simulator is hard to simulate the complex light environment of the tunnel. Thus, the exit advance guide signs are set at $500 \mathrm{~m}$ ahead of the tunnel exit

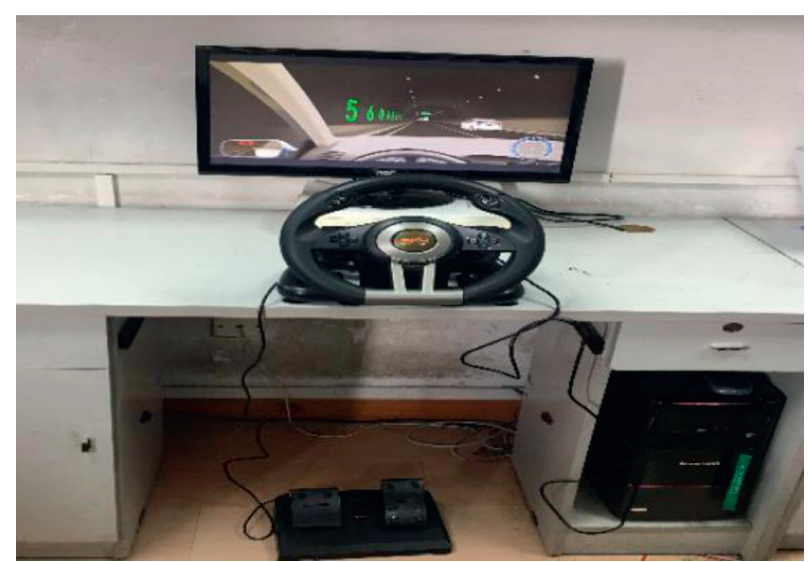

FIGURE 1: Driving simulator.

TABle 1: Maximum traffic volumes corresponding to different service levels of the highway.

\begin{tabular}{lc}
\hline Service levels & Maximum traffic volume $(\mathrm{Q} / \mathrm{pcu} / \mathrm{h})$ \\
\hline First level & 550 \\
Second level & 1,200 \\
Third level & 1,550 \\
\hline
\end{tabular}

to avoid the adverse effect of the "white hole effect" on the visibility of the sign.

The proposed separated exit guide signs included location and distance signs, as shown in Figure 2. Location signs were set in the middle of the top of the tunnel. According to "Road traffic signs and markings" (GB-5768.22009 ) and "Specification for road traffic signs and markings" (JTG D82-2009) standards, the height chosen of Chinese characters is $40 \mathrm{~cm}$, which is related to speed. Distance signs were placed $62.6 \mathrm{~m}$ from location signs, with a character height and width of $1.5 \mathrm{~m}$ and a total sign length of $22.5 \mathrm{~m}$.

According to the design of most mountainous highways in China, the basic experiment was set on a dual-lane highway with a design speed of $80 \mathrm{~km} / \mathrm{h}$. As most cars were driven in the left lane, and lane changing was not allowed in the tunnel according to Chinese traffic rules, driving in the right lane was not considered. When a vehicle was driven in the left lane, it was forced to change the lane after leaving the tunnel to enter the exit ramp; however, it was not necessary when driving in the right lane. Therefore, this paper only simulates the scene of the car driving in the left lane.

3.4. Test Data Processing. The FORUM 8 simulation platform is used to export 42 groups of test data, including time, speed, acceleration, vehicle location, steering wheel angle, and vehicle location offset data. Due to the mass data exported by the simulation platform, $\mathrm{R}$ language programming software is used to calculate the mean value of multiple data within every $1 \mathrm{~m}$ in the data with $1 \mathrm{~m}$ as a scale, which can better compare the influence of driving speed, acceleration, and other variables on tunnel group-outletinterchange spacing under different working conditions. 
TABle 2: Test scheme.

\begin{tabular}{lcccccc}
\hline Working condition & 1 & 2 & 3 & 4 & 5 & 6 \\
\hline Spacing $(\mathrm{m})$ & 300 & 300 & 350 & 350 & 400 & 400 \\
Sign location & Top & Top and sidewall & Top & Top and sidewall & Top & Top and sidewall \\
\hline
\end{tabular}

Spacing is the distance from tunnel exit to starting point of ramp entry deceleration lane.

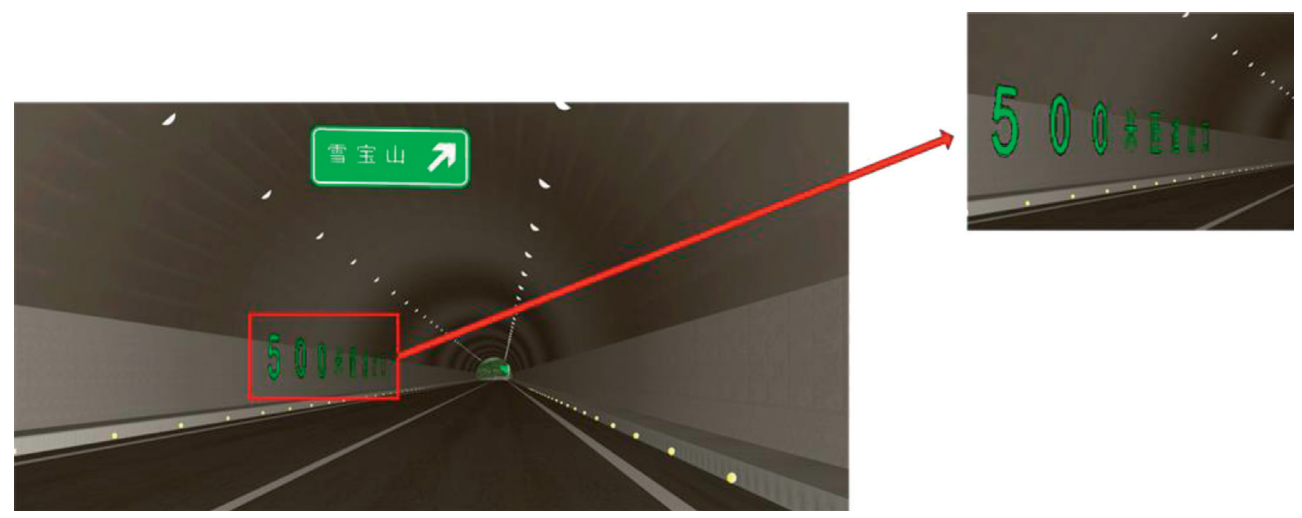

FIGURE 2: Location sign + distance sign.

In this paper, the Pauta criterion in statistics is used to eliminate abnormal data. In the $X-Y$ coordinate system, some data exceed the detection range in the $X$ and $Y$ directions, and these abnormal data need to be eliminated. At the same time, there are certain errors in the data obtained from the experiment, which will also lead to the generation of abnormal data. The specific formula of the Pauta criterion method is expressed as

$$
\left|x_{i}-\bar{x}\right|>3 \sigma .
$$

When the difference between the value of a data $x_{i}$ in the sample and the average value of the sample is greater than 3 times the standard deviation of the sample, the data is abnormal and should be discarded.

\section{Results and Discussion}

4.1. Vehicle Trajectory. In order to describe the running track of the test vehicle conveniently, the test model is shown in Figure 3.

Taking the left edge as the reference line, the trajectory offset data of vehicles after driving out of the tunnel were collected by UC-win/Road. The mean value of the obtained data from 42 groups of participants was calculated after removing the outliers; thus, vehicle trajectories under different highway service levels and working conditions were obtained (Figures 4-6).

Figures 4-6 display the variation trends of the traverse distances of vehicles during the lane change operation. By analyzing the significance, we found that the vehicle trajectories under different working conditions of the different service levels differed greatly. The position where the vehicle trajectories crossed the lane line was regarded as the intermediate point of lane shift, and the backward calculation method was employed to calculate the starting position and distance of vehicle shift. The calculated results are presented in Table 3, where the transverse distance $\left(L_{2}\right)$ indicates the distance between the vehicle position and the tunnel exit.

The following inferences can be drawn by analyzing Table 3.

(1) Under the same working condition, the starting position of vehicle transverse movement at the first service level was significantly smaller than that at the second and third service levels. When the service level is the first level, second level, and third level, within the allowable lane change range, the initial transverse location of the vehicle in the test group is $13.39 \%, 21.20 \%$, and $5.73 \%$ earlier than that in the comparison group, and the lane change distance is shortened by $6.34 \%, 20.18 \%$, and $15.34 \%$, indicating that when the designed service traffic at the first service level was much smaller than that at the second and third service levels and the interference of surrounding vehicles on driving vehicles was small, the drivers took the lane change operation earlier to ensure sufficient safety confirmation distance. When traffic increases to a certain extent, with the increase in the traffic volume, the change of the initial transverse location of vehicles was not obvious.

(2) Under different service levels and the same working condition, the distance between the location of vehicles crossing the lane line and the tunnel exit increased with the increase in the service level. Taking working condition 1 as an example, the location of the vehicle crossing the lane line is $130 \mathrm{~m}$ from the tunnel exit and the vehicle transverse distance is $102 \mathrm{~m}$ under the first level. The location of the vehicle crossing the lane line is $231 \mathrm{~m}$ away from the tunnel exit and the vehicle transverse distance is $135 \mathrm{~m}$ under the second level. The location of the vehicle 


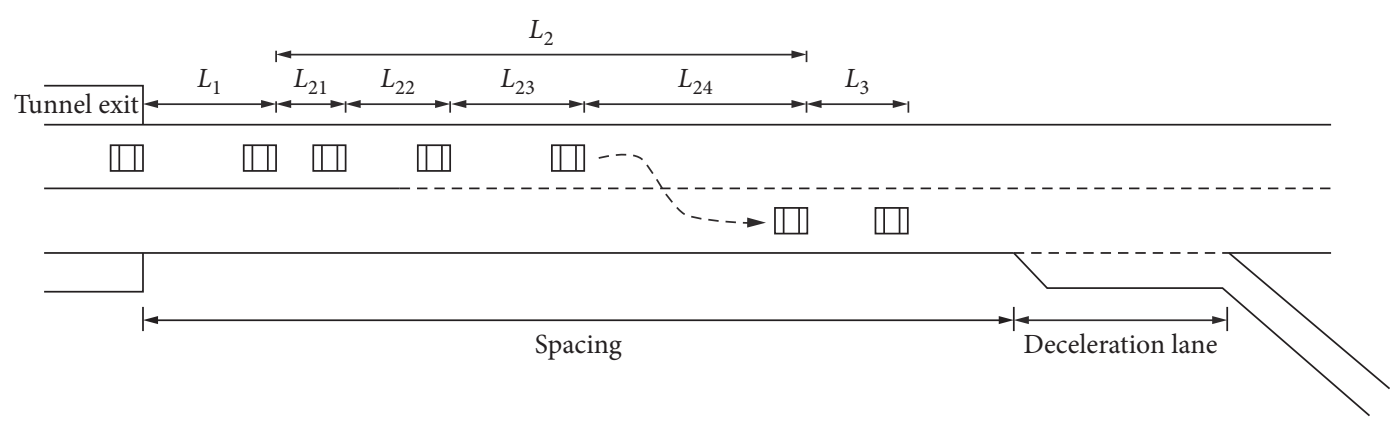

Figure 3: Test model. $L_{1}$ is the "light adaptation" distance; $L_{2}$ is the traverse distance; $L_{21}$ is the wait insertion distance; $L_{22}$ determines whether it is the distance of the inserted gap; $L_{23}$ is the adjusting distance; $L_{24}$ is the transverse distance to the inner lane; $L_{3}$ is the safety confirmation distance.

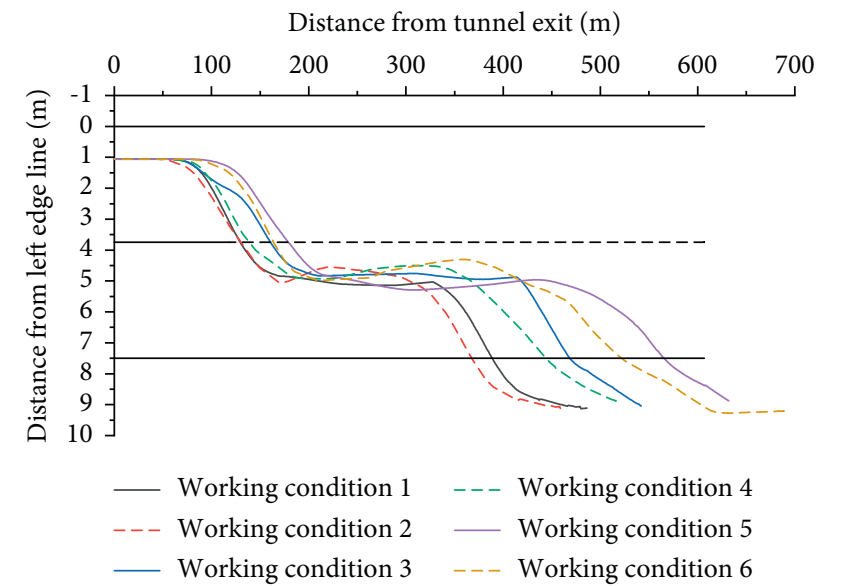

Figure 4: Vehicle trajectories under different working conditions of the first service level.

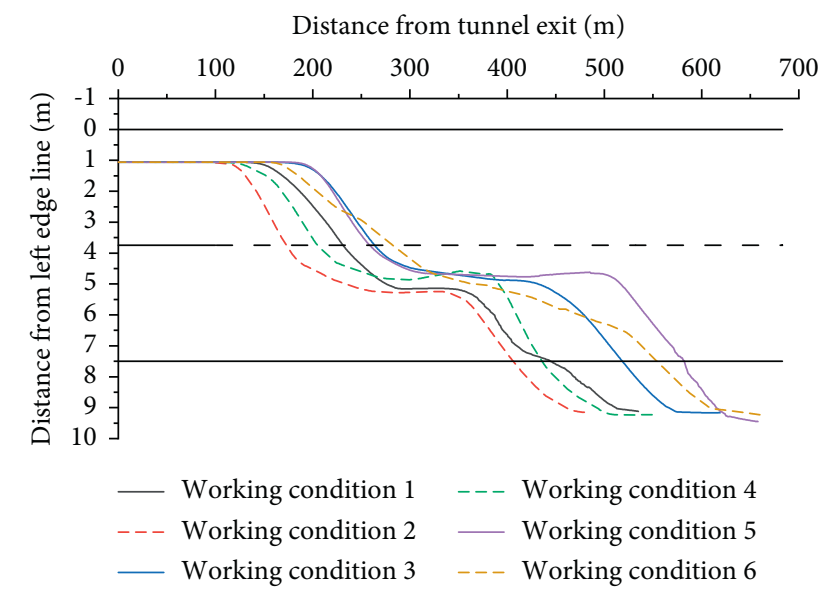

FIGURE 5: Vehicle trajectories under different working conditions of the second service level.

crossing the lane line is $283 \mathrm{~m}$ away from the tunnel entrance and the vehicle transverse distance is $187 \mathrm{~m}$ under the third level. The rest working conditions have this rule. Therefore, with the increase in traffic volume at the tunnel exit, the lateral distance of vehicles to the inner lane also increased. The reason

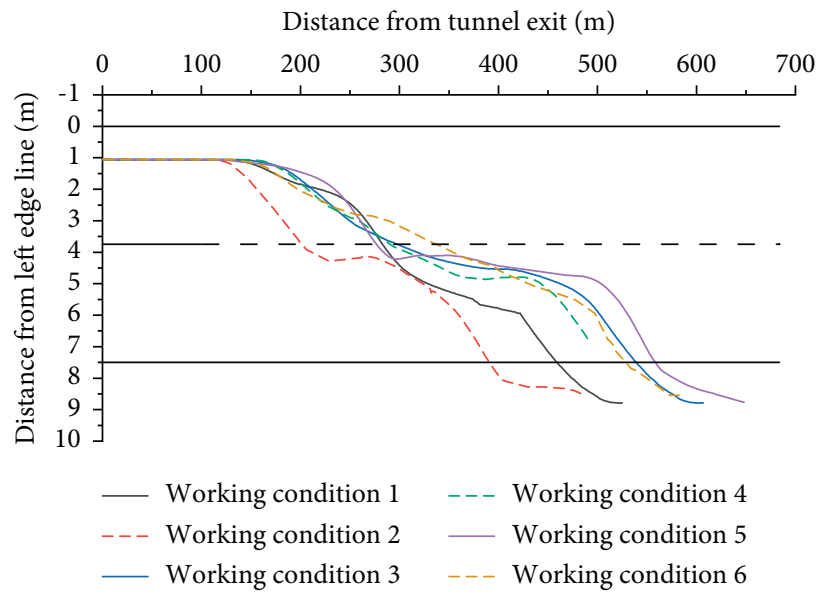

FIGURE 6: Vehicle trajectories under different working conditions of the third service level.

is that with the increase of traffic volume, the driver's choice of lane change time is limited by the surrounding vehicles, usually taking slow driving in the original lane to seek lane change time, so the vehicle's lateral distance will increase.

(3) Under the same service level, the starting location of vehicle transverse displacement of each test group was closer than that of their corresponding comparison group. Under the same service level, the starting location of each test group is closer than that of the corresponding comparison group. For example, under the first level, the starting location of working condition 2 is $44 \mathrm{~m}$, which is closer than that of working condition 1 , which is $59 \mathrm{~m}$; the starting locations of working conditions 4 and 6 are $61 \mathrm{~m}$ and $76 \mathrm{~m}$; and the starting locations of working conditions 3 and 5 are $67 \mathrm{~m}$ and $83 \mathrm{~m}$, which have the same rule. It shows that setting the distance sign of the tunnel sidewall has a guiding effect on the driver, so that the driver understands the distance of the front ramp, has certain psychological expectations for the ramp exit, and can complete the lane change in advance within a limited distance to ensure sufficient safety confirmation distance. 
TABle 3: Vehicle traverse position.

\begin{tabular}{|c|c|c|c|c|c|}
\hline Service level & Working condition & $\begin{array}{l}\text { Traverse starting } \\
\text { position }(\mathrm{m})\end{array}$ & $\begin{array}{l}\text { Lane change } \\
\text { position }(\mathrm{m})\end{array}$ & $\begin{array}{l}\text { Traverse ending } \\
\text { position }(\mathrm{m})\end{array}$ & Transverse distance $(\mathrm{m})$ \\
\hline \multirow{6}{*}{ First level } & 1 & 59 & 130 & 161 & 102 \\
\hline & 2 & 44 & 130 & 155 & 111 \\
\hline & 3 & 67 & 162 & 200 & 133 \\
\hline & 4 & 61 & 139 & 178 & 117 \\
\hline & 5 & 83 & 180 & 211 & 128 \\
\hline & 6 & 76 & 165 & 188 & 112 \\
\hline \multirow{6}{*}{ Second level } & 1 & 129 & 231 & 264 & 135 \\
\hline & 2 & 105 & 172 & 214 & 109 \\
\hline & 3 & 160 & 264 & 360 & 200 \\
\hline & 4 & 110 & 205 & 264 & 154 \\
\hline & 5 & 178 & 260 & 398 & 220 \\
\hline & 6 & 153 & 284 & 333 & 180 \\
\hline \multirow{6}{*}{ Third level } & 1 & 128 & 283 & 315 & 187 \\
\hline & 2 & 108 & 201 & 312 & 204 \\
\hline & 3 & 138 & 299 & 441 & 303 \\
\hline & 4 & 149 & 292 & 360 & 211 \\
\hline & 5 & 153 & 277 & 478 & 325 \\
\hline & 6 & 138 & 337 & 413 & 275 \\
\hline
\end{tabular}

(4) Taking the first level as an example, in the three different working conditions of the test group and the comparison group, the starting location of vehicle transverse movement in working condition 6 $(76 \mathrm{~m})$ is greater than that in working condition 4 $(61 \mathrm{~m})$, and the starting location of vehicle transverse movement in working condition $4(61 \mathrm{~m})$ is greater than that in working condition $2(44 \mathrm{~m})$. The starting location of vehicle lateral movement in working condition $5(83 \mathrm{~m})$ is greater than that in working condition $3(67 \mathrm{~m})$, and the starting location of vehicle lateral movement in working condition 3 $(67 \mathrm{~m})$ is greater than that in working condition 1 $(59 \mathrm{~m})$, which also has this rule under the second and third service levels. It is found that when the distance between the tunnel-interchange spacing increases from $300 \mathrm{~m}$ to $500 \mathrm{~m}$, the driver is freer to choose the time of lane change. In order to ensure sufficient $L_{23}$ (adjusting distance), the driver generally changes lane later, so the starting location of the transverse movement is also larger.

(5) The function of the deceleration lane is to enable the vehicle to drive at a safe speed when entering the ramp, so as to avoid skidding, rollover, or hitting the guardrail. The driver can change to the right lane earlier in the upstream of the deceleration lane, which is an important guarantee for the safe deceleration of the vehicle. From the diagram of vehicle trajectory, it can be obtained that under the three service levels, the distance of transverse ending position in the experimental group was less than that in the comparison group, and the difference was the most significant under the second and third service levels. For example, under the second service level, the transverse ending position in working condition 4 is $96 \mathrm{~m}$ ahead of that in condition 3 . Therefore, it can be shown that the separated exit advance guide signs proposed in this paper can provide effective driving information for drivers and complete lane change operation quickly and safely, complete the lane change operation, and drive into the deceleration lane to slow down, avoiding the driver due to the lack of exit guidance information. The adverse conditions such as forced lane change or missing the interchange exit in a short distance have a good effect on improving the road traffic safety guarantee vehicle from the expressway tunnel to the interchange exit section to effectively slow down on the deceleration lane and drive into the ramp.

4.2. Vehicle Speed and Acceleration within $200 \mathrm{~m}$ after Driving Out of the Tunnel. The speed and acceleration data of vehicles within $200 \mathrm{~m}$ after driving out of the tunnel under different working conditions were collected by the UC-win/ Road simulation software. Taking the tunnel exit as the zero point, the speed and acceleration data of vehicles under different working conditions were studied. The mean values of the obtained data from 42 groups of participants under each working condition were calculated, and abnormal data were eliminated according to the Pauta criterion. The vehicle speed and acceleration curves within $200 \mathrm{~m}$ after the tunnel exit under the first, second, and third service levels and different working conditions are displayed in Figures 7-9.

The vehicle running speed at the tunnel exit under each working condition $\left(V_{1}\right)$, the vehicle running speed at $200 \mathrm{~m}$ outside the tunnel exit $\left(V_{2}\right)$, the absolute value of average acceleration $(|\bar{a}|)$, the difference between $V_{1}$ and the design speed $\left(\Delta V_{1}\right)$, and the difference between $V_{2}$ and design speed $\left(\Delta V_{2)}\right.$ are presented in Table 4.

The following inferences can be drawn by analyzing Figures 7-9 and Table 4. 


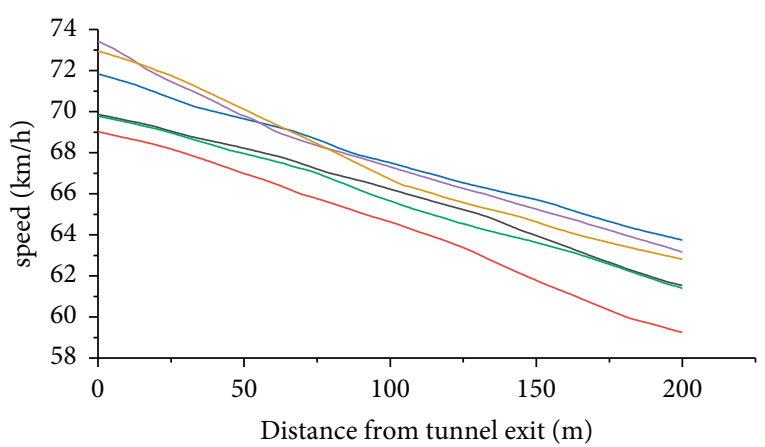

$\begin{array}{rr}- \text { Working condition } 1 & - \text { Working condition } 4 \\ - \text { Working condition } 2 & - \text { Working condition } 5 \\ \text { Working condition } 3 & - \text { Working condition } 6\end{array}$

(a)

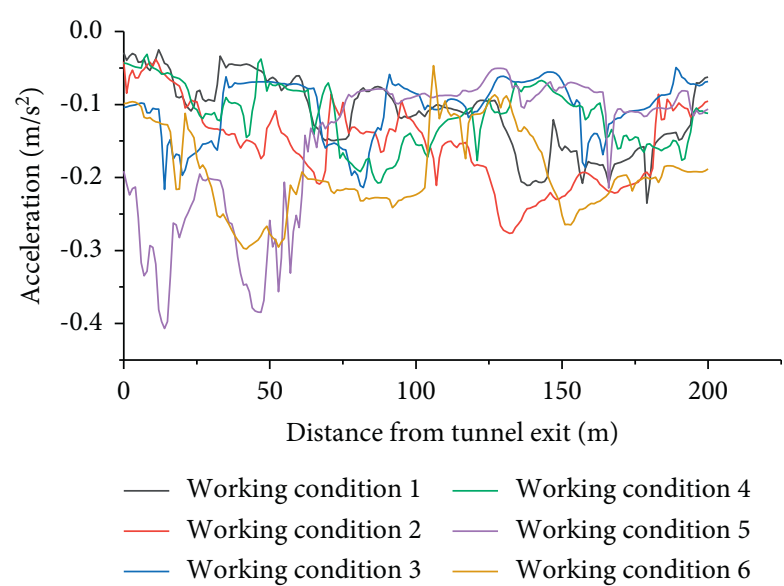

(b)

Figure 7: Vehicle speed and acceleration curves within $200 \mathrm{~m}$ after the tunnel exit in the first service level. (a) Speed curve (b) Acceleration curve.

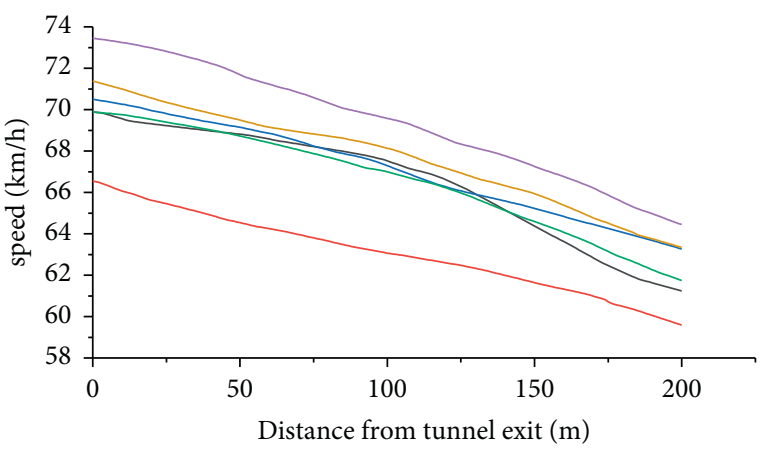

$\begin{array}{rr}\text { Working condition } 1 & \text { Working condition } 4 \\ - \text { Working condition } 2 & - \text { Working condition } 5 \\ - \text { Working condition } 3 & - \text { Working condition } 6\end{array}$

(a)

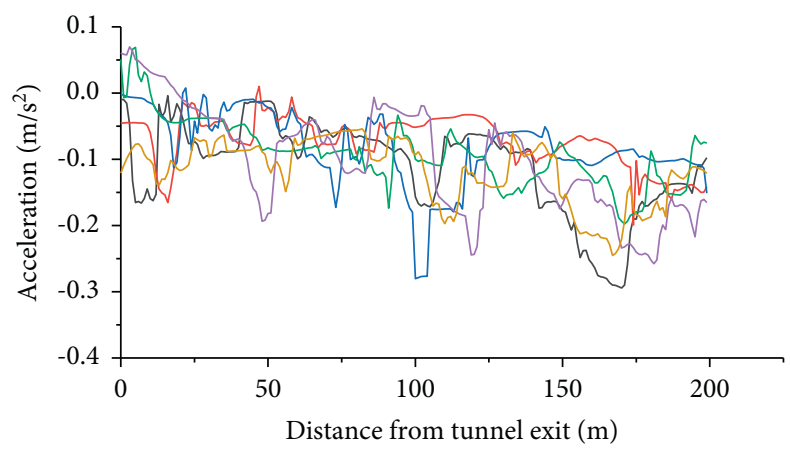

$\begin{array}{rr}\text { Working condition } 1 & - \text { Working condition } 4 \\ - \text { Working condition } 2 & - \text { Working condition } 5 \\ - \text { Working condition } 3 & \text { Working condition } 6\end{array}$

(b)

Figure 8: Vehicle speed and acceleration curves within $200 \mathrm{~m}$ after the tunnel exit in the second service level. (a) Speed curve (b) Acceleration curve.

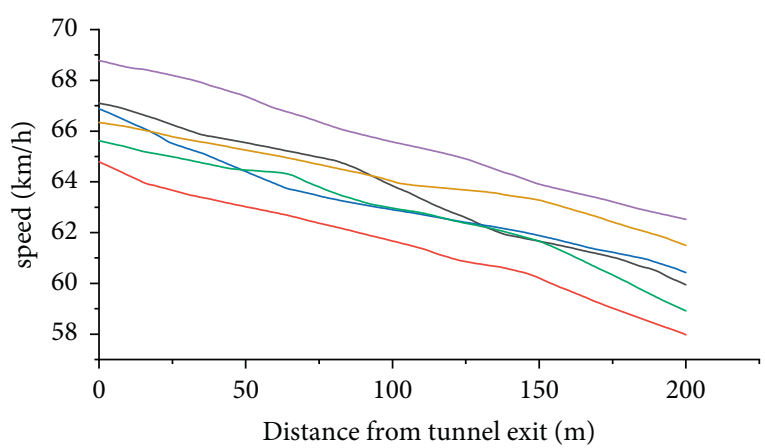

$\begin{array}{rr}\text { Working condition } 1 & - \text { Working condition } 4 \\ - \text { Working condition } 2 & - \text { Working condition } 5 \\ \text { Working condition } 3 & - \text { Working condition } 6\end{array}$

(a)

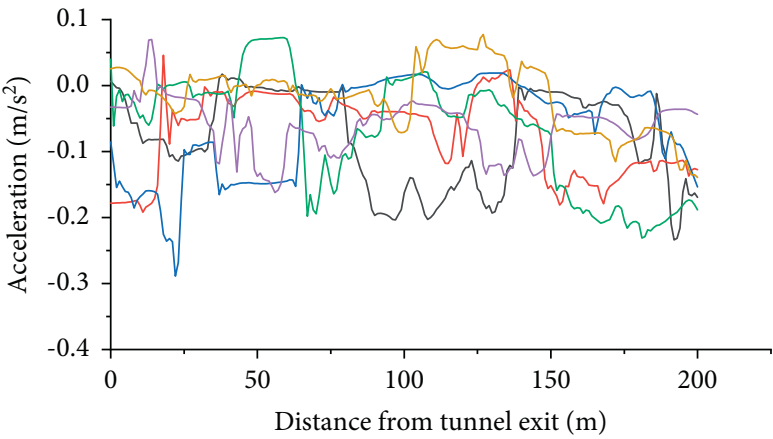

\begin{tabular}{rr} 
Working condition 1 & Working condition 4 \\
- Working condition 2 & Working condition 5 \\
\hline & Working condition 3
\end{tabular}

(b)

Figure 9: Vehicle speed and acceleration curves within $200 \mathrm{~m}$ after the tunnel exit in the third service level. (a) Speed curve (b) Acceleration curve. 
Table 4: Average speed and acceleration at different sections within $200 \mathrm{~m}$ after the tunnel exit.

\begin{tabular}{|c|c|c|c|c|c|c|}
\hline Service level & Working condition & $V_{1}(\mathrm{~km} / \mathrm{h})$ & $V_{2}(\mathrm{~km} / \mathrm{h})$ & $|\bar{a}|\left(\mathrm{m} \cdot \mathrm{s}^{-2}\right)$ & $\Delta V_{1}(\mathrm{~km} / \mathrm{h})$ & $\Delta V_{2}(\mathrm{~km} / \mathrm{h})$ \\
\hline \multirow{6}{*}{ First level } & 1 & 69.86 & 61.53 & 0.11 & 10.14 & 18.47 \\
\hline & 2 & 69.03 & 59.24 & 0.10 & 10.97 & 20.75 \\
\hline & 3 & 71.83 & 63.75 & 0.13 & 8.16 & 16.26 \\
\hline & 4 & 69.78 & 62.20 & 0.10 & 10.21 & 17.80 \\
\hline & 5 & 73.42 & 64.44 & 0.19 & 6.58 & 15.56 \\
\hline & 6 & 72.94 & 63.38 & 0.12 & 7.06 & 16.62 \\
\hline \multirow{6}{*}{ Second level } & 1 & 69.89 & 61.28 & 0.11 & 10.11 & 18.72 \\
\hline & 2 & 66.55 & 59.63 & 0.07 & 13.45 & 20.37 \\
\hline & 3 & 70.50 & 63.30 & 0.09 & 9.50 & 16.70 \\
\hline & 4 & 69.71 & 61.79 & 0.08 & 10.29 & 18.21 \\
\hline & 5 & 73.41 & 63.16 & 0.12 & 6.59 & 16.84 \\
\hline & 6 & 71.38 & 62.81 & 0.10 & 8.62 & 17.19 \\
\hline \multirow{6}{*}{ Third level } & 1 & 67.09 & 59.95 & 0.08 & 12.90 & 20.05 \\
\hline & 2 & 64.79 & 57.98 & 0.07 & 15.21 & 22.02 \\
\hline & 3 & 66.87 & 60.42 & 0.06 & 13.13 & 19.58 \\
\hline & 4 & 65.61 & 58.92 & 0.07 & 14.38 & 21.08 \\
\hline & 5 & 68.78 & 62.52 & 0.06 & 11.22 & 17.48 \\
\hline & 6 & 66.34 & 61.49 & 0.02 & 13.66 & 18.51 \\
\hline
\end{tabular}

(1) The vehicle speed in each service level under six different working conditions within $200 \mathrm{~m}$ of the tunnel exit decreased gradually. Moreover, the vehicle speed of each test group was lower than that of their corresponding comparison group. For example, under the first level, the speed change of working condition 2 was reduced from $69 \mathrm{~km} / \mathrm{h}$ to $59 \mathrm{~km} / \mathrm{h}$, and the speed change of working condition 1 was reduced from $70 \mathrm{~km} / \mathrm{h}$ to $62 \mathrm{~km} / \mathrm{h}$. Under the same abscissa, the speed of working condition 2 was less than that of working condition 1 . It is noticeable that the designed traffic signs were inductive. As the distance information between the tunnel group and the interchange exit was provided in the tunnel, the drivers could reduce the vehicle speed as soon as possible after leaving the tunnel and change the lane in advance, reducing rearend accidents caused by excessive speed differences.

(2) From the acceleration curve (b) of all service levels, it can be seen that the change trend of acceleration of the test group was more gentle than that of the comparison group, and the change range is small. Under the same service level, the absolute value of the average acceleration of the test group was less than that of the comparison group. For example, under the first service level, the working conditions 2,4 , and 6 were $0.10,0.10$, and 0.12 , and the working conditions 1,3 , and 5 were $0.11,0.13$, and 0.19 . When exit advance guide signs were set on the sidewall of the tunnel, the change of vehicle acceleration was significantly less.

(3) Except for working condition 1 in the first service level, under the same working condition, $\Delta V_{1}$ under each working condition in the first service level was lower than that in the second service level and $\Delta V_{1}$ under each working condition in the second service level was lower than that in the third service level. Taking working condition 2 as an example, the first service level $\Delta V_{1}=10.97<$ the second service level $\Delta V_{1}=13.45<$ the third service level $\Delta V_{1}=15.21$. Except for working condition 2 in the first service level, under the same working condition, $\Delta V_{2}$ under each working condition in the first service level was lower than that in the second service level and $\Delta V_{2}$ under each working condition in the second service level was lower than that in the third service level. Taking working condition 1 as an example, the first service level $\Delta V_{2}=18.47<$ the second service level $\Delta V_{2}=18.72<$ the third service level $\Delta V_{2}=20.05$. With the decrease of service level, traffic volume increases, and the running vehicle is greatly affected by the surrounding vehicles when changing lanes. The difference between the running speed and the design speed will increase, and the driving comfort will decrease. This is consistent with the research results of Zhu et al. [46].

4.3. Vehicle Speed and Acceleration before and after the Lane Change Operation. The mean values of the obtained data from each working condition in three different service levels were calculated. The vehicle speed and acceleration curves within $200 \mathrm{~m}$ before and after the lane change position under different working conditions in each service level are presented in Figures 10-12.

Taking the position where the vehicles crossed the lane line as the reference point, the speed and acceleration data within $100 \mathrm{~m}$ before and after the reference point were analyzed. In order to expedite the calculation process, vehicle positions across the lane line were taken, and the obtained results are presented in Table 5.

The average vehicle speeds of the test and comparison groups before $100 \mathrm{~m}$ of the lane line crossing position, the average speeds before $50 \mathrm{~m}$ of the lane line crossing position, the average speeds at the lane line crossing position, the average speeds after $50 \mathrm{~m}$ of the lane line crossing position, the average speeds after $100 \mathrm{~m}$ of the lane line crossing position, and the total average speeds are presented in Table 6. 


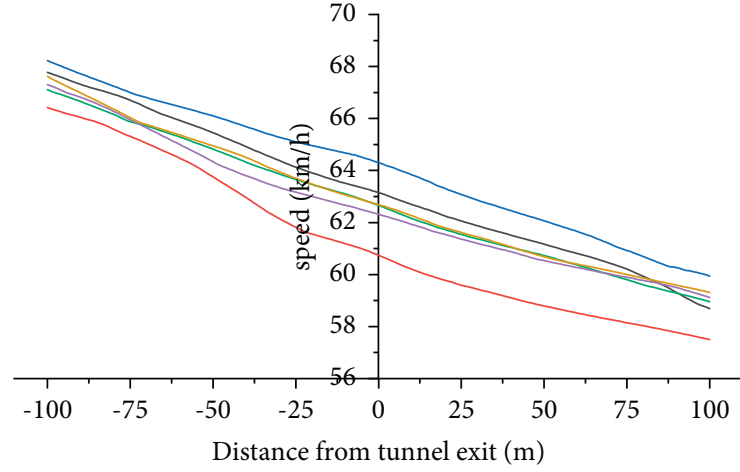

Working condition 1
Working condition 2
- Working condition 3

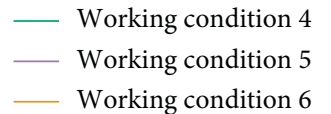

(a)

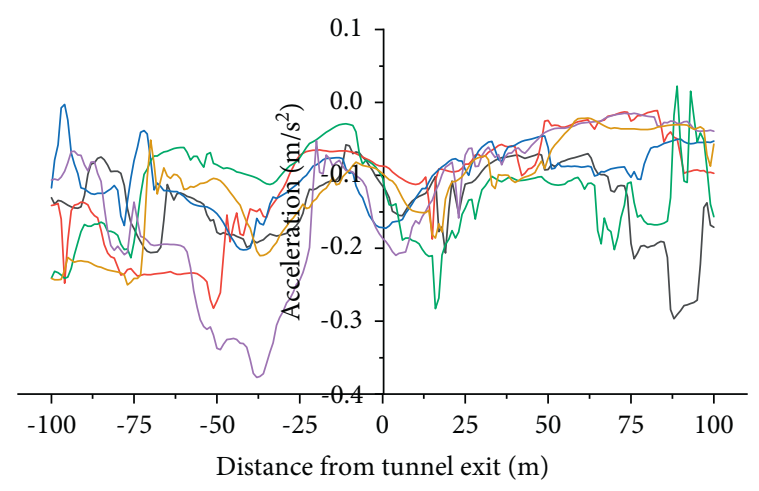

$\begin{array}{ll}\text { Working condition } 1 & - \text { Working condition } 4 \\ \text { Working condition } 2 & - \text { Working condition } 5 \\ \text { Working condition } 3 & - \text { Working condition } 6\end{array}$

(b)

Figure 10: Vehicle speed and acceleration curves within $200 \mathrm{~m}$ before and after the lane change position in the first service level. (a) Speed curve. (b) Acceleration curve.

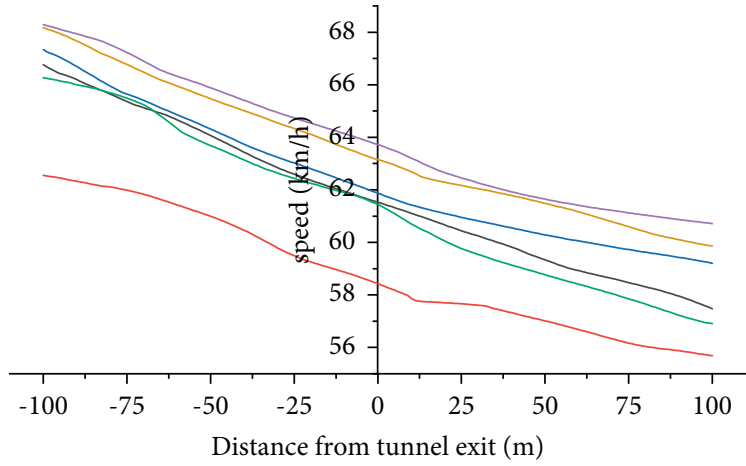

Distance from tunnel exit (m)
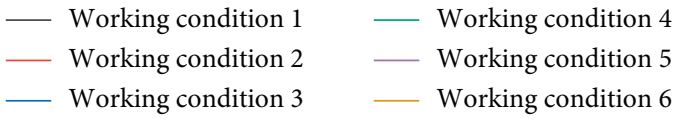

(a)

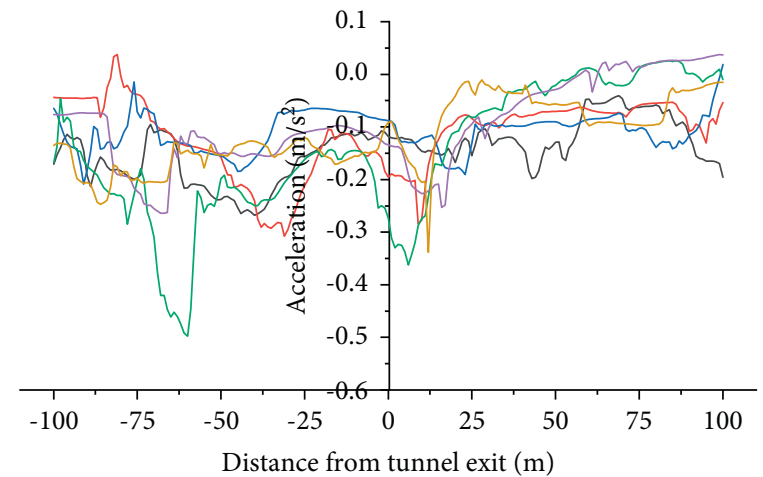

Working condition 1
- Working condition 2
- Working condition 3

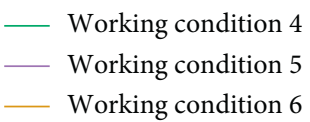

(b)

Figure 11: Vehicle speed and acceleration curves within $200 \mathrm{~m}$ before and after the lane change position in the second service level. (a) Speed curve. (b) Acceleration curve.

The following inferences can be drawn by analyzing Figures 9-11 and Tables 5-6:

(1) The vehicle speed in each service level under six different working conditions tended to decrease before and after the lane line crossing position; thus, the vehicles got into the traffic flow on the right during the lane change operation.

(2) It can be seen from Table 6 that the speed of each section of the text group was lower than that of the comparison group under the first, second, and third service levels, and the average speed of the test group is $1.44 \%, 2.40 \%$, and $0.08 \%$ lower than that of the comparison group, indicating that the driver reduces the speed to carry out lane change in advance and the warning effects of the exit advance guide signs are better than those of the tunnel top sign only.

(3) Under each service level, the acceleration of the six working conditions in the range of $200 \mathrm{~m}$ before and after the vehicle lane change is less than 0 , indicating that the vehicle has deceleration behavior. In order to compare and analyze the (b) group diagram of Figures 9-11, it is found that the acceleration change in the comparison group is larger and the acceleration change rate is larger. For example, the acceleration curve of working condition 1 and working condition 5 under the first service level has a sharp rise and fall curve section, indicating that the driver has a sharp brake or forced lane change behavior during the lane change. However, the change trend 


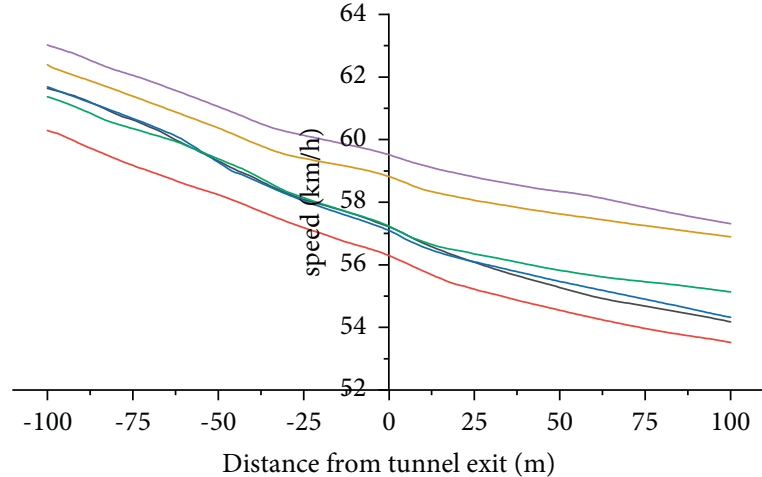

Working condition 1
Working condition 2
Working condition 3

— Working condition 4

- Working condition 5

Working condition 6

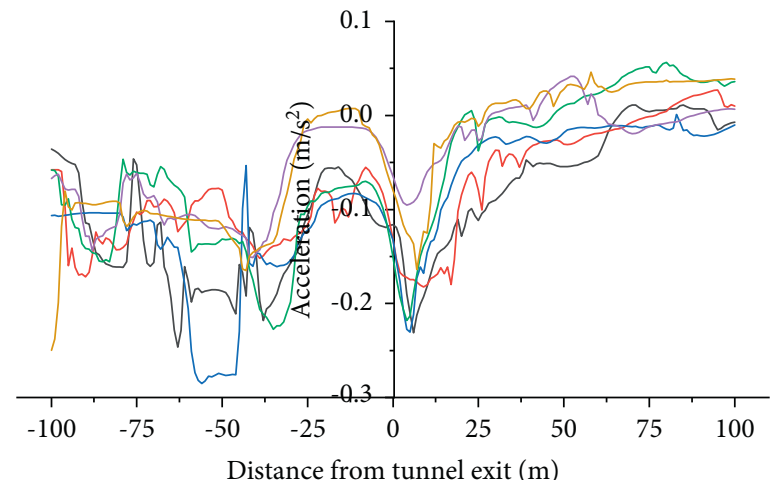

(a)

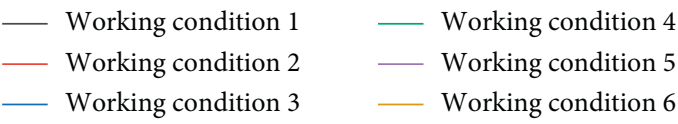

(b)

Figure 12: Vehicle speed and acceleration curves within $200 \mathrm{~m}$ before and after the lane change position in the third service level. (a) Speed curve. (b) Acceleration curve.

TABLE 5: Vehicle speed and acceleration within $100 \mathrm{~m}$ before and after the lane change position.

\begin{tabular}{|c|c|c|c|c|c|c|c|}
\hline $\begin{array}{l}\text { Service } \\
\text { level }\end{array}$ & $\begin{array}{l}\text { Working } \\
\text { condition }\end{array}$ & $\begin{array}{l}\text { Before } 100 \mathrm{~m} \\
(\mathrm{~km} / \mathrm{h})\end{array}$ & $\begin{array}{c}\text { Before } 50 \mathrm{~m} \\
(\mathrm{~km} / \mathrm{h})\end{array}$ & $\begin{array}{c}\text { At the lane line crossing } \\
\text { position }(\mathrm{km} / \mathrm{h})\end{array}$ & $\begin{array}{c}\text { After } 50 \mathrm{~m} \\
(\mathrm{~km} / \mathrm{h})\end{array}$ & $\begin{array}{l}\text { After } 100 \mathrm{~m} \\
(\mathrm{~km} / \mathrm{h})\end{array}$ & $\begin{array}{c}\text { Acceleration } \\
\left(\mathrm{m} \cdot \mathrm{s}^{-2}\right)\end{array}$ \\
\hline \multirow{6}{*}{ First level } & 1 & 67.78 & 65.45 & 63.15 & 61.17 & 58.69 & -0.14 \\
\hline & 2 & 66.42 & 63.76 & 60.74 & 58.79 & 57.50 & -0.11 \\
\hline & 3 & 68.22 & 66.10 & 64.30 & 62.06 & 59.93 & -0.14 \\
\hline & 4 & 67.11 & 64.82 & 62.66 & 60.73 & 58.96 & -0.09 \\
\hline & 5 & 67.30 & 64.34 & 62.32 & 60.53 & 59.12 & -0.14 \\
\hline & 6 & 67.62 & 64.95 & 62.69 & 60.68 & 59.30 & -0.11 \\
\hline \multirow{6}{*}{$\begin{array}{l}\text { Second } \\
\text { level }\end{array}$} & 1 & 66.76 & 64.07 & 61.53 & 59.33 & 57.48 & -0.14 \\
\hline & 2 & 62.56 & 60.99 & 58.43 & 57.01 & 55.69 & -0.12 \\
\hline & 3 & 67.34 & 64.32 & 61.87 & 60.29 & 59.20 & -0.15 \\
\hline & 4 & 66.27 & 63.68 & 61.44 & 58.77 & 56.91 & -0.11 \\
\hline & 5 & 68.29 & 65.89 & 63.72 & 61.64 & 60.72 & -0.09 \\
\hline & 6 & 68.18 & 65.47 & 63.15 & 61.48 & 59.87 & -0.12 \\
\hline \multirow{6}{*}{ Third level } & 1 & 61.64 & 59.32 & 57.21 & 55.28 & 54.20 & -0.10 \\
\hline & 2 & 60.29 & 58.24 & 56.30 & 54.55 & 53.54 & -0.08 \\
\hline & 3 & 61.69 & 59.28 & 57.10 & 55.47 & 54.34 & -0.09 \\
\hline & 4 & 61.37 & 59.39 & 57.23 & 55.83 & 55.15 & -0.06 \\
\hline & 5 & 63.02 & 61.05 & 59.52 & 58.34 & 57.33 & -0.04 \\
\hline & 6 & 62.39 & 60.37 & 58.82 & 57.62 & 56.91 & -0.04 \\
\hline
\end{tabular}

TABLE 6: Average speeds within $100 \mathrm{~m}$ before and after the lane change position.

\begin{tabular}{|c|c|c|c|c|c|c|c|}
\hline $\begin{array}{l}\text { Service } \\
\text { level }\end{array}$ & Group & $\begin{array}{l}\text { Before } 100 \mathrm{~m} \\
(\mathrm{~km} / \mathrm{h})\end{array}$ & $\begin{array}{c}\text { Before } 50 \mathrm{~m} \\
(\mathrm{~km} / \mathrm{h})\end{array}$ & $\begin{array}{l}\text { At the lane line crossing } \\
\text { position }(\mathrm{km} / \mathrm{h})\end{array}$ & $\begin{array}{c}\text { After } 50 \mathrm{~m} \\
(\mathrm{~km} / \mathrm{h})\end{array}$ & $\begin{array}{l}\text { After } 100 \mathrm{~m} \\
(\mathrm{~km} / \mathrm{h})\end{array}$ & $\begin{array}{c}\text { Average speed } \\
(\mathrm{km} / \mathrm{h})\end{array}$ \\
\hline \multirow[t]{2}{*}{ First level } & $\begin{array}{c}\text { Comparison } \\
\text { group }\end{array}$ & 67.77 & 65.30 & 63.25 & 61.25 & 59.24 & 63.36 \\
\hline & Test group & 67.05 & 64.51 & 62.03 & 60.07 & 58.59 & 62.45 \\
\hline \multirow{2}{*}{$\begin{array}{l}\text { Second } \\
\text { level }\end{array}$} & $\begin{array}{c}\text { Comparison } \\
\text { group }\end{array}$ & 67.46 & 64.76 & 62.37 & 60.42 & 59.13 & 62.83 \\
\hline & Test group & 65.67 & 63.38 & 61.01 & 59.09 & 57.49 & 61.32 \\
\hline \multirow{2}{*}{$\begin{array}{l}\text { Third } \\
\text { level }\end{array}$} & $\begin{array}{c}\text { Comparison } \\
\text { group }\end{array}$ & 62.12 & 59.88 & 57.94 & 56.36 & 55.29 & 58.32 \\
\hline & Test group & 61.35 & 59.33 & 57.45 & 56.01 & 55.20 & 57.87 \\
\hline
\end{tabular}


of acceleration in the test group is more gentle than it. According to the existing research of Yang et al. [47], the lower the change rate of acceleration, the higher the driver's driving comfort. Therefore, the exit advance guide signs set in this paper have a certain effect on improving the driver's driving safety and comfort.

\section{Conclusion}

This paper proposed the exit advance guide signs in a tunnel by using a driving simulator. By changing the signs placement positions, tunnel-interchange spacings, and traffic volumes, we obtained the influences of exit advance guide signs on the trajectory and speed of passenger cars in highway tunnels. The results show that when the service level is the first level, second level, and third level, compared with setting exit guide sign only at the top of the tunnel, the separated exit advance guide signs in the tunnel proposed in this paper makes the initial transverse position of the vehicle from the tunnel exit advance by $13.39 \%, 21.20 \%$, and $5.73 \%$, the lane change distance is shortened by $6.34 \%, 20.18 \%$, and $15.34 \%$, the average speed is decreased by $1.44 \%, 2.40 \%$, and $0.08 \%$, and the acceleration is reduced to $-0.10 / \mathrm{m} \cdot \mathrm{s}^{-2},-0.11$ / $\mathrm{m} \cdot \mathrm{s}^{-2}$, and $-0.06 / \mathrm{m} \cdot \mathrm{s}^{-2}$. Therefore, under the premise of ensuring safety and comfort, the separated exit advance guide signs in the tunnel with different service levels, tunnel exit-interoperability, and different spacing are better. Effective advance guide signs would contribute to the improved service level, road capacity, and operation of urban highways. Some scholars have studied advanced guide signs of closely spaced exit ramps on urban highways [15] and evaluated the effectiveness of traffic guide signs at intersections [24]. No research has been carried out on evaluating the exit advance guide signs according to the trajectory and speed of passenger cars. This study can provide a theoretical basis for engineering applications and support the optimization of exit advance guide signs design in a tunnel. The main limitation of the paper lies in only considering a twolane single-hole tunnel with a speed limit of $80 \mathrm{~km} / \mathrm{h}$. In fact, different driving speeds have a certain impact on the driver's identification of objects. This paper only studies the straightline tunnel, but it is more difficult for the driver to accurately perceive the speed and maintain the trajectory in the curve section. In future research, we should pay attention to the influence of different linear tunnels on the speed and trajectory of the driver. In addition, this paper did not consider the driver's heart rate, blood pressure, and other psychological indicators, and the lighting of the tunnel between the real world and the driving simulator is different; however, these physiological indexes could be considered in future work.

\section{Data Availability}

Driving behaviors under six different test schemes were investigated by a driving simulator. A driving simulator can create nearly any driving scenario and collect vehicle speed and position data at any resolution. The speed and trajectory data of cars were collected by the driving simulator to conduct an in-depth analysis of driving behavior.

\section{Conflicts of Interest}

The authors declare no conflicts of interest.

\section{Acknowledgments}

This work was supported by the Science and Technology Research Program of Chongqing Municipal Education Commission (Grant no. KJQN201900722), the Science and Technology Bureau Foundation and Frontier Project of Chongqing (Grant nos. cstc2019jcyj-msxmX0695), and the Graduate Research and Innovation Project of Chongqing Jiaotong University (Grant no. 2021S0033).

\section{Supplementary Materials}

This article provides the original data of each picture, including trajectory, velocity, and acceleration data. (Supplementary Materials)

\section{References}

[1] Z. G. Du, Y. H. Tang, J. Xie, and P. F. Li, "New research on improved highway tunnel based on visual illusion," in Proceedings of the Transportation Reform and Change-Equity, Inclusiveness, Sharing, and innovation-Proceeding of the 17th COTA Interation Conference of Transportation Professionals, pp. 4369-4379, Shanghai, China, January 2018.

[2] S. Bassan, "Overview of traffic safety aspects and design in road tunnels," IATSS Research, vol. 40, no. 1, pp. 35-46, 2016.

[3] T. D. Ceunynck, C. Ariën, K. Brijs et al., "Proactive evaluation of traffic signs using a traffic sign simulator," European Journal of Transport and Infrastructure Research, vol. 15, no. 2, p. 15, 2015.

[4] https://www.sohu.com/a/233460419_275988.

[5] V. Melnicuk, S. Thompson, P. Jennings, and S. Birrell, "Effect of cognitive load on drivers' State and task performance during automated driving: introducing a novel method for determining stabilisation time following take-over of control," Accident Analysis \& Prevention, vol. 151, Article ID 105967, 2021.

[6] Q. Y. Yang, Y. Chen, C. Wu, S. M. Easa, W. Lin, and X. Zheng, "Effect of highway directional signs on driver mental workload and behavior using eye movement and brain wave," Accident Analysis \& Prevention, vol. 146, Article ID 105705, 2020.

[7] H. J. Foy and P. Chapman, "Mental workload is reflected in driver behaviour, physiology, eye movements and prefrontal cortex activation," Applied Ergonomics, vol. 73, pp. 90-99, 2018.

[8] N. C. Lyu, Y. Cao, L. Qin, and C.-Z. Wu, "Research on the effectiveness of driving workload based on traffic sign information volume," China Journal of Highway and Transport, vol. 31, no. 8, pp. 165-172, 2018.

[9] Design Specification for Highway Alignment, JTG D20-2017.

[10] Specifications for design of highway tunnel, JTG 3370.1-2018.

[11] Road traffic signs and markings, GB 5768.2-2009.

[12] Guidelines for design of highway grade-separated intersections, JTG/T D21-D2014. 
[13] J. Xu, Q. Luo, J. C. Mao, and Y. M. Shao, "Method for horizontal geometry design of mountainous roads based on trajectory-speed cooperative control," China Journal of Highway and Transport, vol. 26, no. 4, 2013.

[14] H. Feng, "Research on the establishment of traffic signs and marking in two-lane mountain highway," Master thesis, Jilin University, Jilin, China, 2007.

[15] T. Shang, H. Lu, P. Wu, and X. Lu, "Method of setting exit advance guide signs in highway tunnels based on the driver's eye movement with Markov chains," IEEE Access, vol. 9, pp. 24079-24092, 2021.

[16] L. H. Huang, X. H. Zhao, Y. Li et al., "Optimal design alternatives of advance guide signs of closely spaced exit ramps on urban expressways," Accident Analysis \& Prevention, vol. 138, Article ID 105465, 2020.

[17] X. Yao, X. Zhao, H. Liu, L. Huang, J. Ma, and J. Yin, “An approach for evaluating the effectiveness of traffic guide signs at intersections," Accident Analysis \& Prevention, vol. 129, pp. 7-20, 2019.

[18] W. Z. Wang and B. H. Liu, "Automatic recognition algorithm of traffic signs in road tunnel," Informatics in Control, Automation and Robotics, pp. 677-683, Springer, Berlin, Germany, 2011.

[19] J. Upchurch, D. Fisher, R. A. Carpenter, and A. Dutta, "Freeway guide sign design with driving simulator for central artery-tunnel: boston, Massachusetts," Transportation Research Record: Journal of the Transportation Research Board, vol. 1801, no. 1, pp. 9-17, 2002.

[20] H. Lu, T. Shang, Y. Wei, and P. Wu, "Safety assessment of exit advance guide signs in mountainous highway tunnel based on eye-tracking Technology," IEEE Access, vol. 9, pp. 111315111325, 2021.

[21] B. Yan, J. B. Zhou, and L. Wang, "Effectiveness of traffic sign setting in adjacent tunnel exit," Procedia Social and Behavioral Sciences, vol. 96, pp. 5-11, 2013.

[22] H. T. Zwahlen, A. Russ, J. M. Roth, and T. Schnell, "Effectiveness of ground-mounted diagrammatic advance guide signs for freeway entrance ramps," Transportation Research Record: Journal of the Transportation Research Board, vol. 1843, no. 1, pp. 70-80, 2003.

[23] L. Fang, H. Min, Z. Teng, and M. Feng, "A guide sign optimization problem for an added road based on bird mating optimizer," in Proceedings of the International Conference on Swarm Intelligence, Springer, Fukuoka, Japan, August 2017.

[24] H. Bai, L. Yu, T. Zhang, D. Xie, and N. Cui, "Locating speed limit signs for freeway tunnel entrance and exit," in Proceedings of the International Conference on Transportation and Development, connected and autonomous vehicles and transportation safety, Vancouver, Canada, 2018.

[25] D. Arup, C. Rick, A. David, and Noyce, "Drivers' understanding of overhead freeway exit guide signs," Evaluation of Alternatives with an Advanced Fixed-Base Driving Simulator, vol. 1803, no. 1, pp. 102-109, 2002.

[26] C. Dong, S. S. Nambisan, K. Xie, D. B. Clarke, and X. Yan, "Analyzing the effectiveness of implemented highway safety laws for traffic safety across U.S. states," Transportmetrica: Transport Science, vol. 13, no. 2, pp. 91-107, 2017.

[27] K. Al-Sahili and M. Dwaikat, "Modeling geometric design consistency and road safety for two-lane rural highways in the west bank, Palestine," Arabian Journal for Science and Engineering, vol. 44, no. 5, pp. 4895-4909, 2019.

[28] M. Kazemi, A. M. Rahimi, and S. Roshankhah, "Impact assessment of effective parameters on drivers' attention level to urban traffic signs," Journal of The Institution of Engineers (India): Series A, vol. 97, no. 1, pp. 63-69, 2016.

[29] F. Malin and J. Luoma, "Effects of speed display signs on driving speed at pedestrian crossings on collector streets," Transportation Research Part F: Traffic Psychology and Behaviour, vol. 74, pp. 433-438, 2020.

[30] A. Akbari and F. Haghighi, "Traffic calming measures: an evaluation of four low-cost TCMs' effect on driving speed and lateral distance," IATSS Research, vol. 44, no. 1, pp. 67-74, 2020.

[31] R. Van Houten and F. Van Huten, "The effects of a specific prompting sign on speed reduction," Accident Analysis \& Prevention, vol. 19, no. 2, pp. 115-117, 1987.

[32] D. Shinar and M. Vogelzang, "Comprehension of traffic signs with symbolic versus text displays," Transportation Research Part F: Traffic Psychology and Behaviour, vol. 18, pp. 72-82, 2013.

[33] Y. C. Song, H. X. Liu, and S. F. Ge, "Quantitative evaluation of the position of an interchange advance guide sign based on traffic simulation technology," in Proceedings of the CICTP 2014: Safe, Smart, and Sustainable Multimodal Transportation Systems, pp. 2653-2659, Beijing, China, July 2014.

[34] T. Y. Guo, W. Deng, J. S. Hou, and J. Lu, "Placement distance of freeway exit advance guide sign and its safety impacts share," Journal of Southeast University, vol. 26, no. 4, pp. 622-627, 2010.

[35] Q. Y. Peng, J. Xu, Q. Luo, and Y. Shao, "Effect of horizontal curves design on track and speed of passenger car," Journal of Tongji University, vol. 40, no. 1, pp. 45-50, 2012.

[36] J. L. Vilchez, "Representativity and univocity of traffic signs and their effect on trajectory movement in a driving-simulation task: regulatory signs," Journal of Safety Research, vol. 66, pp. 101-111, 2018.

[37] J. L. Vilchez, "Effects of mental footnotes on the trajectory movement in a driving simulation task," Journal of Motor Behavior, vol. 47, no. 3, pp. 211-225, 2015.

[38] J. L. Vilchez, "Representativity and univocity of traffic signs and their effect on trajectory movement in a driving simulation task: warning signs," Traffic Injury Prevention, vol. 18, no. 5, pp. 544-549, 2017.

[39] J. Hang, X. Yan, L. Ma, K. Duan, and Y. Zhang, "Exploring the effects of the location of the lane-end sign and traffic volume on multistage lane-changing behaviors in work zone areas: a driving simulator-based study," Transportation Research Part F: Traffic Psychology and Behaviour, vol. 58, pp. 980-993, 2018.

[40] A. Calvi, M. R. De blasiis, and C. Guattari, "An empirical study of the effects of road tunnel on driving performance," Procedia-Social and Behavioral Sciences, vol. 53, pp. 10981108, 2012.

[41] B. Liang, T. Liu, Y. Xiao, and X. Zhang, "Experimental on relationship between traffic signs and drivers' perception at exit of extra-long tunnel," Journal of Chang'an University: Natural Science Edition, vol. 40, no. 5, pp. 48-55, 2020.

[42] S. H. Jung, "Design and analysis of cancer clinical trials for personalized medicine," Journal of Personalized Medicine, vol. 11, no. 5, p. 376, 2021.

[43] B. Geis, S. Tulka, S. Knippschild, and F. Krummenauer, "Introduction of a user-oriented application for biometrical sample size calculation in clinical and epidemiological trials," Klinische Monatsblatter fur Augenheilkunde, vol. 238, no. 2, pp. 179-185, 2019.

[44] L. Meuleners and M. Fraser, "A validation study of driving errors using a driving simulator," Transportation Research 
Part F: Traffic Psychology and Behaviour, vol. 29, pp. 14-21, 2015.

[45] D. R. Mayhew, H. M. Simpson, K. M. Wood, L. Lonero, K. M. Clinton, and A. G. Johnson, "On-road and simulated driving: concurrent and discriminant validation," Journal of Safety Research, vol. 42, no. 4, pp. 267-275, 2011.

[46] Z. Zhu, Y. Lu, C. Fu, and T. Xu, "Research on the safety audit methods for two-lane highway based on HRV," Mathematical Problems in Engineering, vol. 2014, Article ID 308028, 6 pages, 2014.

[47] S. W. Yang, J. L. Xu, H. Z. Yang, and B. Pan, "The lateral change of acceleration in evaluation and control of highway design," Journal of Xi an Highway University, vol. 21, no. 1, pp. $46-48,2000$. 